\title{
ASPECTOS MÉDICOS DEL ARTE SEPARATORIA DE DIEGO DE SANTIAGO
}

\author{
Francisco Teixidó Gómez \\ Doctor en Ciencias Biológicas - U.N.E.D. - I.E.S. Sta. Eulalia - Mérida
}

\section{RESUMEN}

Diego de Santiago, destilador en el monasterio de El Escorial, es una figura fundamental para comprender la tardía influencia que el paracelsismo tuvo en España. El presente trabajo muestra, en muchos aspectos, su separación manifiesta de los saberes y actitudes de los profesionales de la salud y de la medicina tradicional.

Por otro lado, en el pensamiento científico del extremeño se entremezclan, en otras ocasiones, el galenismo tradicional y la orientación química de la obra médica de Paracelso.

\section{SUMMARY}

Diego de Santiago, an alchemist at «El Escorial», is a key figure to understand the late influence that Paracelsus had in Spain. This work shows how he differs from the medical authorities of his day and traditional medicine.

On the other hand, Galenic medical thought and Paracelsus' chemical Medicine intermingle in the Extremenian scientific work.

\section{INTRODUCCIÓN.}

El pueblo cacereño de San Martín de Trebejo vio nacer, a mediados del siglo XVI, la figura más destacada del paracelsismo en España: Diego de Santiago.

Pocas son las noticias que tenemos de él: trabajó en su pueblo natal, Zamora, El Escorial y Sevilla. Escribió un pequeño folleto con consejos prácticos sobre la peste, Preservativos contra la peste, que vio la luz en Sevilla en 1599. Sin embargo, la obra por la que merece toda consideración es el Arte separatoria, publicada, en dos libros, en la misma ciudad en $1598^{1}$. El título completo de la misma es: Arte separatoria y

1 Santiago, D. (1598), Arte separatoria. Francisco Pérez, Sevilla. Los Tomos I y II de la obra serán referenciados como a y $\mathrm{b}$ respectivamente.

Los dos libros del Arte separatoria constan de 230 folios y fueron escritos, probablemente, de forma independiente lo cual es deducible por el hecho de las abundantes repeticiones de temas generales y de 
modo de apartar todos los Licores, que se sacan por vía de Destilación: para que las Medicinas obren con mayor virtud y presteza. Completa la portada de la misma la profesión del autor, «Destilador de su Majestad», y su vecindad, Sevilla².

No sabemos si el libro tuvo una gran acogida por parte de los alquimistas, boticarios, etc. Sí conocemos que Juan de Castro y Medianilla, boticario cordobés, escribió en 1619 El Arte de Destilar, manuscrito que no se llegó a publicar y que se conserva en la Biblioteca Nacional de Madrid, en el que sin citar a Santiago se refiere a él ${ }^{3}$ de esta manera: «y un autor moderno en un libro harto bien excusado por su inutilidad...» ${ }^{4}$. Sin embargo, el benedictino Fray Esteban Villa, considerado como uno de los más insignes farmacéuticos de su época, cita en sus obras a nuestro autor ${ }^{5}$.

Diego de Santiago escribe en lengua vulgar y no en latín; en la España científica del siglo XVI se escribe en latín y en romance y aunque los que lo hicieron de esta manera recibieron ataques de los primeros ${ }^{6}$, es obvia la existencia de un fuerte movimiento en favor de la lengua vulgar para difundir los conocimientos científicos. Por otra parte, creo conveniente recordar que una figura de la talla de René Descartes escribe en el Discurso del método (1637): «Y si escribo en francés, que es la lengua de mi país, en lugar de hacerlo en latín, que es el idioma empleado por mis preceptores, es porque creo que los que hagan uso de su pura razón natural juzgarán mejor mis opiniones que los que sólo creen en los libros antiguos» ${ }^{7}$. Además, y como muy bien se ha dicho, respecto de las obras sobre las aplicaciones científicas hay que tener en cuenta que «escribir en castellano acerca de estas materias resultaba muy a menudo mucho más difícil que hacerlo en un latín adocenado, por la necesidad de ir

asuntos concretos que se observan en los dos tomas de la obra. El Arte separatoria está dedicado a don Francisco Arias de Ávila y Bobadilla, Conde de Puñonrostro y Asistente de Sevilla.

2 He consultado la edición facsímil del ejemplar que se conserva en la Biblioteca Universitaria de Salamanca, publicado por el Instituto de Cultura «Juan Gil-Albert» (Diputación de Alicante). Alicante, 1994. La referida edición posee un espléndido estudio introductorio de 49 páginas realizado por LÓPEZ PiÑERo, J. M.y PORTELA MARCO, E.

3 Sabemos que el personaje aludido es Diego de Santiago porque su cita anónima sobre la calidad de los vidrios concuerda con la del extremeño. Véase: SANTIAGO, D. (1598a), pp. 3 y 4.

4 Cita trancrita de MuÑoz CAlvo, S. (1994), Historia de la Farmacia en la España moderna y contemporánea. Síntesis. Madrid, p. 141.

5 Las obras más significativas de este benedictino, en las que se nombra a de Santiago, son: Examen de boticarios. (Pedro de Huydobro. Burgos, 1632.) y Ramillete de Plantas medicinales (Gómez de Valdivieso. Burgos, 1637)

6 En este sentido Francisco Arceo escribió en latín y criticó con gran acritud a los que utilizaban el romance por considerar que era una forma de estimular el intrusismo de aquellos profesionales sin formación académica. 105.

7 DESCARTES, R. (1991). Discurso del método. Meditaciones metafísicas. Espasa-Calpe. Madrid, p. 
creando una terminología inexistente en lengua vulgar» ${ }^{8}$. La opinión al respecto, del extremeño es tajante:

\begin{abstract}
«Y los que verdaderamente supieren y entendieren la verdad por la naturaleza, mientras en menos lenguas se saben menos confusión causan, porque cuando la cosa se ve no tenemos necesidades de alegaciones. Y cuando la hemos de saber, mejor entenderemos nuestra lengua que las extrañas, y esto digo porque entienden muchos que si no se saben las cosas por latín que no harán ni imprimirán sus calidades en los casos que se ofrecieren, y engáñanse porque el latín no añade la virtud a lo que se aplica, ni el romance se lo quita, que el que lo supiere bien por romance también obrará con ello como el latino...»9.
\end{abstract}

El siglo XVI es el siglo de la primera revolución científica: se empieza a dejar de lado el «conocimiento clásico», se abandona en gran medida la especulación escolástica y Aristóteles, Galeno, Hipócrates, etc. son puestos en tela de juicio. Son los albores del método experimental que empiezan a propugnar los sabios de la época, Leonardo, Vesalio, Berengario, Paracelso, etc. En el ámbito de la química es un siglo de transición suave entre la alquimia tradicional y la moderna, un siglo en el que los «científicos», sin dejar de tener rasgos alquímicos empiezan a abandonar las doctrinas más clásicas.

El siglo XVI es dominado por una etapa de tránsito entre la medicina medieval y la moderna en la que conviven la medicina tradicional y las aportaciones de algunos médicos $\mathrm{y}$, contrariamente a lo que pudiera parecer, se inicia con una vuelta atrás: la lectura directa de los textos clásicos permite depurarlos de los errores de las traducciones medievales. Como consecuencia del nuevo espíritu renacentista, muchos médicos realizan comentarios a los textos que traducen, lo que contribuye a reducir, no a eliminar, el criterio de autoridad de los clásicos. A pesar de todo, la decimosexta centuria es eminentemente galénica ya que los métodos experimentales relativos al conocimiento fisiológico no emergen en la actividad científica hasta el siglo siguiente. Sin embargo, la clara parcelación observable entre la ciencia más o menos institucionalizada y la cultura extraacadémica se pierde, en cierta medida, en el Renacimiento y, a pesar de que el siglo XVI es, en el aspecto médico, eminentemente galénico, se aprecia una apertura a otras corrientes intelectuales: el neoplatonismo, el atomismo clásico, la filosofía natural estoica, la astrología, la tradición hermética y la alquimia ${ }^{10}$.

8 LóPeZ Piñero, J. M. (1979). En GONZÁlez BlasCo, P.; JimÉNEZ BlanCO, J. y LóPEZ Piñero, J. M. Historia y sociología de la ciencia en España. Alianza. Madrid, p. 26.

9 SANTIAGO, D. (1598a), p. 29.

10 BARONA, J. Ll. (1993), Sobre medicina y filosofía natural en el Renacimiento. Seminari d'Estudis sobre la Ciència. Valencia. 


\section{PARACELSO Y El PARACELSISMO.}

Una de las personalidades más sobresalientes del siglo del que nos estamos ocupando fue Philippus Aureolus Theophrastus Bombast Von Hohenheim, o por otro nombre Paracelso (1493-1541). Nacido en Einsideln (Suiza), violento y estrafalario personaje, furibundo opositor de la ciencia clásica, intentó rehacer todos los conocimientos de la medicina de la época despreciando los saberes tradicionales, aun siendo un profundo conocedor de Galeno. Su centro de preocupación fue la medicina ${ }^{11}$, pero relacionó esta disciplina con otros saberes: alquimia, filosofía y religión que provocaron los recelos de la ortodoxia religiosa y científica.

La aparición de la iatroquímica por un lado y la difusión de la obra de Paracelso por otro fueron los pilares fundamentales del asentamiento, a lo largo del siglo XVI, de la práctica química en la actividad farmacéutica.

Para el médico de Einsideln, la enfermedad es un proceso químico de carácter local, idea contraria al galenismo que consideraba la enfermedad como una discrasia de los humores; sin embargo, una gran parte de sus remedios es de origen galénico: «sigue utilizando un arsenal terapéutico de origen esencialmente vegetal, al que añade la botica de inmundicias, tan antigua como el propio afán sanador y presente en el medioevo en la obra de la monja Hildegarda» ${ }^{12}$.

Paracelso considera que la alquimia debe impregnar a la medicina: el médico debe ser un alquimista y éste no debe de buscar la obtención del oro y de la plata, sino preparar remedios curativos; este «creador» de la medicina-química (iatroquímica) dirige su acción a «la búsqueda de compuestos químicos activos (la quinta esencia), principalmente en el mundo vegetal, basándose en la similitud (forma, color...) entre el órgano a tratar y la planta» ${ }^{13}$. Quizás por esto se opone al sistema galénico y se rebela contra la patología tradicional y contra la terapéutica clásica. Según su teoría, hay una perfecta relación entre la vida humana y la del Universo y así, los tres elementos alquímicos, la sal, el azufre y el mercurio, las tria prima, se relacionan con el espíritu, alma y cuerpo humanos. Los tres principios, en proporciones variables, constituyen todas las sustancias de la Naturaleza: «estas tres sustancias -Azufre, Mercurio y Sal- al reunirse componen los cuerpos, a los que nada ya podrá ser añadido, excepto el soplo de la vida y cuanto con él se relacione» ${ }^{14}$.

\footnotetext{
11 Paracelso fue autodidacta, olvidando su titulación en Ferrara.

12 PUerto SARMiento, F.J. (1994), «La farmacia renacentista española y la botica de El Escorial», en La Ciencia en el Monasterio del Escorial, Actas del Simposium (1/4-IX-1993). Ediciones Escurialenses. San Lorenzo de El Escorial (Madrid), p. 122.

13 DOMÈNECH, X. (1993), «Paracelso: el principio del fin de la alquimia». Mundo Científico n1134. Volumen 13. Abril. p. 348.

14 PARACELSO (1992). Obras completas. (Opera omnia). «Libro de las paradojas», Libro I. «Causas y orígenes de las tres primeras sustancias». Renacimiento, C.S.I.C. Sevilla, p. 149-150.
} 
Entre los seguidores europeos del paracelsismo se encuentran el alemán Oswald Croll, autor de la Basilica Chymica (1609), y el francés Turquet de Mayerne, que publica en 1618 la Farmacopea Londinense.

La obra de Paracelso no se conoció en los primeros sesenta años de la España del siglo XVI por dos razones fundamentales: su escasa difusión y la propia idiosincrasia de la ciencia académica española ${ }^{15}$. Sin embargo, al suizo no le eran desconocidas las obras medievales españolas de Arnau de Vilanova, Ramón Llul y Averroes ${ }^{16}$.

En la España de 1552 ve la luz una obra que tuvo una importante difusión dentro y fuera de nuestro país: las Coplas sobre la piedra philosophal del alquimista valenciano Luis de Centelles y, nueve años después, Caravantes publica la Praxis artis alchimicae.

En el último tercio de la decimosexta centuria las cosas cambian considerablemente e importantes profesionales relacionan química y medicina: Juan Fragoso (1530?-1597) es el primer médico español que cita al médico de Einsideln, Francisco Díaz (1530?-1590), Bartolomé Hidalgo de Agüero (1530-1597), etc. Además, sobre la base de las aportaciones de Paracelso, se crea en la ciudad del Turia una cátedra sobre medicamentos químicos al frente de la cual estuvo el protomédico del Reino de Valencia Lorenzo Cóçar ${ }^{17}$.

En una posición intermedia entre la alquimia y la ciencia académica tradicional se encuentra un extravagante personaje: el médico y alquimista boloñés, Leonardo Fioravanti (1518?-1588). En 1576 y 1577 estuvo en España y, en 1582, publicó en Venecia sus cuatro libros Della Fisica, que dedicó a Felipe $\mathrm{II}^{18}$; es admisible, y considero probable, que fuera uno de los responsables de la difusión de las obras de Paracelso dentro del ambiente alquímico español. En cualquier caso, «la principal repercusión de la obra de Paracelso en la España del último tercio del siglo XVI se produce en el terreno de las relaciones entre la destilación y la medicina» ${ }^{19} \mathrm{y}$, en este sentido, la principal personalidad es Diego de Santiago ${ }^{20}$.

15 Para más detalles ver el «Estudio Introductorio» realizado por LÓPEZ PIÑERO, J. M. y PORTELA MARCO, E. (1994), en SANTIAGO, D. (1598), pp. 16-20.

16 En el texto del extremeño no hay referencias a otros autores excepto cuando dice que del arte separatoria «entendieron muy bien Arnaldo de Villanova, y Raimundo Lulio y Theophrasto Paracelso, y Iverquero, y Joannes de Rupecissa». Véase SANTIAGO, D. (1598b), p. 21.

17 La citada cátedra sólo funcionó durante un curso académico (1591-92) debido a la muerte de su impulsor. El texto en el que el médico valenciano exponía su adhesión a Paracelso fue publicado en 1589 y se titulaba Dialogus veros medicinae fontes indicans. Para más detalles puede consultarse LóPEZ PIÑERO, J.M. (1977), El «Dialogus» (1589) del paracelsista Llorenç Cocar y la cátedra de medicamentos químicos de la Universidad de Valencia (1591). Valencia.

18 Las citadas Coplas sobre la piedra philosophal de Luis de Centelles se encuentran al final de la referida obra de Fioravanti.

19 LÓPEZ PiÑERO, J. M. y PORTEla MARCo, E. (1994), en Introducción a SANTIAGO, D. (1598), p. 23.

20 Sobre la obra alquímica de Diego de Santiago puede verse: TEIXIDó GóMEZ, F. y FERRERA ESCUDERO, S. (1998), «Alquimia, química y filosofía alquímica en la obra del extremeño Diego de Santiago». Asclepio, Volumen L, Fascículo 1, pp. 31-47. 
Por otro lado, durante el reinado de Felipe II las instituciones y empresas científicas españolas patrocinadas por la Monarquía adquieren un gran vigor; la expedición científica dirigida por Francisco Hernández (1517-1587), primera de las que se realizaron en el mundo moderno, la madrileña Academia de Matemáticas, la sevillana Casa de Contratación y el Jardín Botánico de Aranjuez son buenos ejemplos del impulso de la Corona a los quehaceres científicos. Pues bien, una de estas instituciones fue el gran laboratorio de «destilación» ubicado en El Escorial.

\section{LA BOTICA DE EL ESCORIAL, LA «CASA PARA DESTILAR LAS AGUAS» Y DIEGO DE SANTIAGO.}

Cuando Felipe II inicia la construcción del monasterio de El Escorial, lo primero que edifica es el claustro de la iglesia pequeña y el de la enfermería, donde se construyeron cuatro celdas y una botica.

El 6 de mayo de 1585 se firma la construcción de la Botica escurialense y dos años más tarde, en el otoño de 1587, debió finalizar la obra arquitectónica. La figura más sobresaliente a la hora de instalar los materiales del laboratorio de destilación fue, quizás, el napolitano Juan Vicencio Forte ${ }^{21}$.

La creación de la Real Botica tiene como objetivo atender a los reyes, su familia y los individuos del servicio regio. No obstante, hasta el final del siglo XVII, la Botica realizó una importante labor asistencial que afectó a conventos de religiosos, mendigos, etc.

En esta institución trabajan siete «profesionales», miembros aprobados por el Protomedicato, a los que se les impide crear su propia botica; se nombra a una personalidad principal, el Boticario Mayor, tres Ayudas y otros tantos Mozos del Oficio; dos peones completan el personal. En la Botica hay un Laboratorio de destilación cuyo máximo responsable, el Destilador Mayor, recibe la ayuda de los trabajadores de aquélla. En este centro escurialense, modelo de la profesión farmacéutica, se orientó la ciencia de una manera muy moderna.

La Botica de la institución escurialense disponía de gran cantidad de medicinas, polvos, tabletas, ungüentos, etc. que habían sido elaborados en la rebotica, la cual disponía de hornos, destiladores, prensas, etc. De todos los aparatos que se encontraban en esta última dependencia, llamaban la atención un horno con sesenta cucúrbitas o retortas para hierbas, flores y raíces, otro de veintitrés comunicadas por tubos de vidrios y la famosa «torre filosofal», que tenía ciento veintiséis alambiques y unos

21 Para más detalles sobre la importancia de Forte puede verse el trabajo de LÓPEZ GAJATE, J. (1994), «La Botica de San Lorenzo el Real de El Escorial». En La Ciencia en el Monasterio del Escorial, Actas del Simposium (1/4-IX-1993). Ediciones Escurialenses. San Lorenzo de El Escorial (Madrid), pp. 297-298. 
cinco metros de altura. Almela nos da una cumplida información de las cinco «oficinas» de la Botica:

\footnotetext{
«es la primera... de las aguas destiladas, y la segunda donde se hacen las destilaciones por dos baños de maría de cada seis alambiques, con los cuales también se hacen los jarabes y un horno de un evaporatorio para sacar aguas destiladas por milagroso artificio...; tiene este evaporatorio treinta y dos alambiques y es cuadrado; la tercera de prensas y morteros, y la cuarta donde están los hornos para el arte clínica donde se sacan quintaesencias y se hace oro potable y cualesquier otros metales y piedras; y la quinta oficina donde están las aguas primeras que dan los materiales de que se sacan las quintaesencias» ${ }^{22}$.
}

Cercana, pero independiente de la «Botica» escurialense, se encontraba lo que Jehan Lhermite, gentilhombre de cámara del monarca español, en su obra Le Passetemps, denominó la «mayson por distiller des eaux» ${ }^{23}$.

En el Laboratorio de destilación de El Escorial trabajan extranjeros como el flamenco Francisco Holbecq ${ }^{24}$, el más antiguo de los «Destiladores de Su Majestad»; el ya citado Juan Vicencio Forte, Richard Stanyhurst, católico exiliado de Inglaterra, y los españoles Juan del Valle, Juan de Ausnero, Juan de Sancten, Justo de Frave y, el más importante de todos, Diego de Santiago. Cuando el italiano Forte nos dice que había cumplido «las frecuentes órdenes de Vuestra Magestad de preparar quintaesencias según la práctica de Ramón Llull para la salud del cuerpo» ${ }^{25}$, nos está dando una buena noticia de la orientación que tenía la destilación que allí se practicaba.

Ahora bien, un centro destilatorio y una botica debían llevar anejos un jardín de plantas con el fin de obtener los materiales de los que habían que realizar las extracciones. La previsión de Felipe II es tal que al jardinero Juan Holbecq, que ya en 1562 tenía a su cuidado los jardines y plantaciones del centro de la península, entre los que el más importante era el de Aranjuez, se le asigna, también, el cuidado del jardín de plantás medicinales de San Lorenzo el Real; así figura en un documento de $1569^{26}$. Las personas que trabajaban en estos huertos medicinales estaban relacionadas con Sevilla, donde llegaban las plantas del continente americano.

22 Cita transcrita por SÁNCHEZ RON, J.M. (1994), «Felipe II, El Escorial y la ciencia europea del siglo XVI». En La Ciencia en el Monasterio del Escorial, Actas del Simposium (1/4-IX-1993). Ediciones Escurialenses. San Lorenzo de El Escorial (Madrid), p. 57.

23 Transcrito por LÓPEZ PIÑERO, J. M. (1992), «Tradición y renovación en la medicina española del renacimiento» En LÓPEZ PIÑERO, J. M. (Coordinador) Viejo y Nuevo continente: La medicina en el encuentro de dos mundos. SANED, p. 70.

$24 \mathrm{Hijo}$ del jardinero flamenco Juan Holbecq, que trabajaba en el jardín de Aranjuez.

25 Cita transcrita por GoODMAN, D. (1990), Poder y penuria. Gobierno, tecnología y ciencia en la España de Felipe II. Alianza, Madrid, p. 34.

26 Este documento fue sacado a la luz por LÓPEZ GAJATE, J. (1994), pp. 331-332 


\section{FRANCISCO TEIXIDÓ GÓMEZ}

Almela enumera unas 90 plantas en los jardines escurialenses, algunas americanas y otras de Oriente; en su mayoría son «mediterráneas, olorosas y ornamentales, 60 distintas, y 27 entre hortalizas y frutales» 27 .

Durante el reinado de los primeros Austrias aparecieron ordenanzas específicas para uso de los boticarios, que afectaban a la utilización de pesas y medidas y a la utilización de alquitaras. En este sentido, se pueden citar textos como el Liber de ratione permiscendi medicamenta quae passim medicis veriunt in usum dum morbis medentur (1555) de Fernando Mena, el Pharmacopeorum omnium que in usu apud nostros pharmacopeos index (1561) de Luis Collado, o el Tratado general de aguas destiladas, pesos y medidas de que los boticarios deben usar por nueva Ordenanza y Mandato de Su Majestad y Su Real Consejo (1592) de Francisco Vallés.

En la primera parte de la obra de Vallés se dice que no se utilicen, en la fabricación de aguas destiladas, alquitaras de cobre, plomo ni de estaño y «mandóse a todos los boticarios de estos reinos, que de aquí en adelante ninguno tenga ni venda agua destilada para tomar por la boca que no sea hecha en alambique de vidrio y en baño» ${ }^{28}$.

Independientemente del grado de cumplimiento del Tratado de Vallés, médico predilecto de Felipe II, Protomédico de todos los Reinos y Señoríos de Castilla y uno de los más prestigiosos de la Europa de la época, parece claro que un Destilador de Su Majestad debía de atenerse a lo escrito por el Médico de Cámara de Su Majestad; por eso, leemos en Santiago que se usan vasos de metal en las preparaciones de las medicinas y, principalmente, de cobre que es de donde salen «las cossas alteradas y privadas de su naturaleza» 29 ; el extremeño defiende el uso del vidrio porque «jamás se a visto azeyte de ninguna yerba que en alquitara fuesse sacada, y en los dichos vidrios todas lo dan y todas lo tienen $»^{30}$.

Además, y lo que es más importante, su espíritu científico le hace comparar los resultados de una destilación realizada en dos alquitaras, una de vidrio y otra de cobre ${ }^{31}$.

\section{EL ARTE SEPARATORIA Y LA ACTITUD DE DIEGO DE SANTIAGO HACIA LOS MÉDICOS.}

Casi al finalizar el primer libro, Santiago nos hace un correcto resumen de lo que es su Arte separatoria:

\footnotetext{
27 Cita transcrita por LORING PALACIOS, J.M. (1994), «Aportación de los destiladores de El Escorial a la fabricación de quintaesencias: materia vegetal empleada en dichas técnicas y un tratado anónimo de destilación (s. XVI) en el ámbito escurialense». En, La Ciencia en el Monasterio del Escorial, Actas del Simposium (1/4-IX-1993). Ediciones Escurialenses. San Lorenzo de El Escorial (Madrid), p. 611.

28 Cita transcrita por LORING PALACIOS, J.M. (1994), pp. 594-595.

29 SANTIAGO, D. (1598a), pp. 46-47.

30 SANTIAGO, D. (1598a), p. 8.

31 SAnTiago, D. (1598a), p. 111.
} 


\section{ASPECTOS MÉDICOS DEL ARTE SEPARATORIA DE DIEGO DE SANTIAGO}

\footnotetext{
«Considerando que ninguna cosa se puede conservar fuera de su individuo, sino se procede con ella con los medios de esta arte separatoria, separando y dividiendo los unos de los otros, y por esta separación se dividen los contrarios y se juntan los concordantes» ${ }^{32}$.
}

En el Libro segundo completa esta definición:

«con él se apartan las sustancias de que están compuestos todos, y si lo ejercitasen los hombres de buen discurso, por él alcanzarían lo oculto de la naturaleza, en lo cual está lo más perfecto» 33 .

Es decir, de una forma implícita se aprecia que, para el extremeño, el organismo es un gran aparato de destilación ya que con los alimentos «hacemos otras muchas preparaciones para que nuestra naturaleza pueda extraer dellas lo que conviene. Y contener la orina y la cámara y otras muchas partes por donde se expele las partes terrestres» ${ }^{34}$. En este sentido no hace más que adherirse al pensamiento de Paracelso: «la naturaleza del Alquimista que hay en cada uno de nosotros, el que por medio de su industria, con los instrumentos y en los reservorios que le son propios, separa los venenos» ${ }^{35}$.

El capítulo 18 de la primera parte del Arte separatoria es muy ilustrativo de lo que supone la justificación de su arte dirigida a médicos y cirujanos; éstos buscan la separación de las causas y, por eso, dice que las dietas, purgas, sangrías, ventosas, fricaciones, fomentaciones, estufas, baños, sahumerios y sudores son los medios usados por los profesionales antes citados «para abrir y dilatar y separar las unas partes de las otras».

El galenismo consideraba que la naturaleza del hombre era consecuencia de la combinación binaria de las cuatro cualidades fundamentales: cálido, frío, seco y húmedo, que serían el origen de los cuatro elementos: aire, fuego, tierra y agua, que combinados originarían los cuatro humores: sangre, flema, cólera y melancolía.

Los cuatro humores de la doctrina médica de Galeno: sangre, bilis amarilla, bilis negra y flema o pituita, son resultantes de la mezcla de los cuatro elementos, que se consideraban concreciones de propiedades opuestas; por ejemplo, el fuego era la concreción de lo seco y cálido y el agua de lo húmedo y frío ${ }^{36}$. Pues bien, esta teoría es admitida por Santiago en el contexto de la alquimia de la época: el agua «junta», el fuego «vivifica», el aire «mueve» y la tierra «recibe».Y según el autor, «nos con-

32 SANTIAGO, D. (1598a), p. 127

33 SANTIAGO, D. (1598b), p. 39.

34 SANTIAGO, D. (1598a), p. 48.

35 PARACELSO (1992). «Libro de las entidades», Segundo «Libro pagano acerca de las entidades morbosas. Tratado de la entidad del veneno». p. 82

36 Para más detalles consultar: «La teoría cualitativa» en SAMBURSKY, S. (1990), El mundo físico a finales de la Antigüedad. Alianza. Madrid. pp. 49-59. 


\section{FRANCISCO TEIXIDÓ GÓMEZ}

viene el agua, y el aire, y el fuego, y la tierra nos es contraria»: por eso hay que «separar estos tres, de este que es inútil» ${ }^{37}$. En efecto, el organismo depura las «partes terrestres» de una manera natural, ya que en ellas se encuentran «humores crudos y viscosos»; por eso, las partes terrestres, son responsables de «muchos acidentes y enfermedades ${ }^{38}$.

Es lógico pensar que la labor que realizaran los destiladores tuviera una aplicación más o menos inmediata, y así nos lo confirma De Santiago: «y muchas vezes me a sucedido tratar y comunicar esta medecina con médicos y cirujanos y maravíllanse cómo puede hazer un agua esos efectos» ${ }^{39}$. En otra ocasión nos informa de su experiencia médica ya que «sanó con ellos [espíritus] enfermedades en quatro, y en cinco, y en seis días, que si fueran curadas con otros medios duraran algunos meses ${ }^{40}$. Además, al finalizar la primera parte de su obra, nos dice que en la población extremeña de la que era natural curó a una mujer casada de gota coral y a otra de asma ${ }^{41}$. Que una personalidad culta y con conocimientos terapéuticos informe de esta circunstancia no debe causarnos extrañeza ya que en la España del siglo XVI, deficitaria en cirujanos y médicos, la labor sanitaria era completada, en gran medida, por curanderos que, incluso con la venia algunas instituciones políticas, ejercían una importante función ${ }^{42}$.

En muchos aspectos la actitud científica del extremeño es eminentemente moderna. Sin respetar el criterio de autoridad, al que se adhieren todavía muchos de sus contemporáneos, es capaz de arremeter contra la verborrea de la ciencia tradicional:

\footnotetext{
«...porque muchas veces acaece tener en las manos lo que conviene para el caso ofrecido, y decir, veamos si lo dijo tal autor, o si no lo dice, si acaso lo dice por diferente sentido: el cual muchas veces no se entiende y dejamos lo que nos conviene y tomamos lo contrario. $\mathrm{Y}$ de estas tales confusiones son libres los que entienden la naturaleza. $\mathrm{Y}$ el que por sola ella caminare, camina en la verdad y no será confundido con la diversidad de las autoridades y pareceres» ${ }^{43}$.
}

Y a los que creen dogmáticamente que la naturaleza no puede ser entendida de mejor manera que como la comprendieron los antiguos les dice que «oy la tenemos tan entera como la tuvieron los que della pueden aver escripto» ${ }^{44}$.

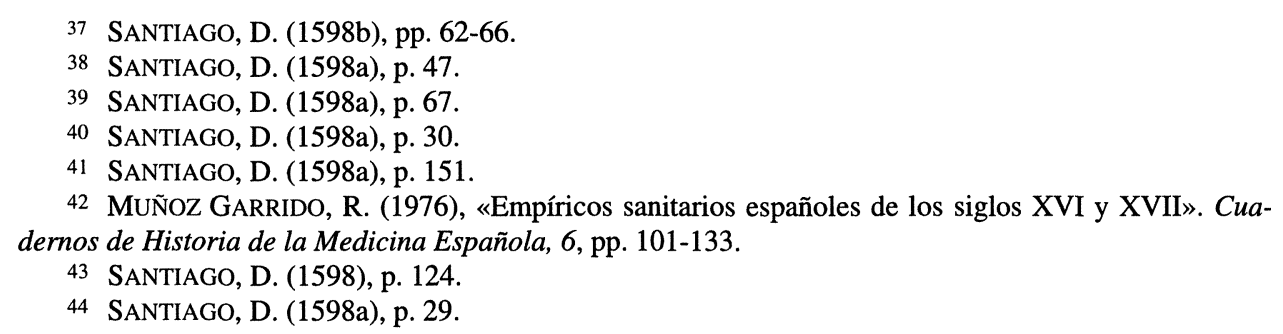


Desde el punto de vista médico, su defensa de la experiencia y como reacción contra las elucubraciones dogmáticas de los galenistas, llega a decir lo siguiente:

\begin{abstract}
«porque lo que ellos leen para ser cierto, ha de ser sacado de ella con experiencia, aunque según los efectos que se ven con la medicina antigua debe haber sido escrita discurriendo con el entendimiento, sin venir a la demostración, y experiencia: lo cual se ve en su variedad, que sucede muchas veces, sobre una enfermedad haber cien pareceres, $y$ todos diferentes y alegados por un autor» ${ }^{45}$.
\end{abstract}

Y es que en este sentido sintoniza perfectamente con Paracelso, para el que «en la vida hay que introducir necesariamente el estudio experimental» ${ }^{46}$.

El extremeño da cuenta de su propia experiencia, tanto de alquimista como de terapeuta; podemos decir que hay cierto «yoísmo» en toda su obra: «yo he hecho», «yo he visto», «yo he curado»...; a veces con machacona redundancia, sea en la primera parte de su obra o en la segunda, al principio o al final: «yo a ocho años que uso dellas en algunas enfermedades», «porque yo he visto muchas personas que tenían grandes ynflamaciones de hígado...», «yo a más de veynte años que uso desta medecina y con ella e visto reparase y sanar...», «yo he visto sanar todos los que an usado desta medicina» ${ }^{47}$. Y todo porque lucha contra el criterio de autoridad, ya que muchos creen «con facilidad lo que se a de creer con gran dificultad» ${ }^{48}$; porque Santiago cree que la experimentación es la única forma de evitar las discusiones estériles de la ciencia tradicional, dado que la medicina antigua «deve aver sido escripta discurriendo con el entendimiento, sin venir a la demostración y experiencia; lo qual se ve en su variedad, que sucede muchas vezes sobre una enfermedad aver cien pareceres, y todos diferentes y alegados por un autor ${ }^{49}$.

De Santiago es muy duro con la falta de conocimientos de algunos profesionales de la medicina; su propia observación le hacer decir que por no «considerar», o lo que es igual según el Tesoro de Covarrubias, por no pensar bien las cosas, «por no conocer las cosas como deven ser conocidas», estando utilizándose un remedio conveniente, se le ha sustituido por otro «que verdaderamente mató al que lo rescivió» ${ }^{50}$.

Por razones éticas, tampoco escapan a sus críticas los médicos y boticarios que por desconocimiento, o para evitar pérdidas económicas, recetan a los enfermos

\footnotetext{
45 SANTIAGO, D. (1598b), p. 22.

46 PARACELSO (1992). «Libro de las paradojas», Libro I. «Causas y orígenes de las tres primeras sustancias», p. 176.

47 Las referencias corresponden a SANTIAGO, D. (1598b), p. 25; y SANTIAGO, D. (1598a), pp. 37 y 26 y 86.

$\begin{array}{ll}48 & \text { Santiago, D. (1598a), p. } 78 . \\ 49 & \text { SAntiago, D. (1598b), p. } 22 . \\ 50 & \text { Santiago, D. (1598a), p. } 32 .\end{array}$
} 


\section{FRANCISCO TEIXIDÓ GÓMEZ}

«medicinas y drogas muchos años viejas y carcomidas» ${ }^{51}$. En este sentido creo que también enlaza perfectamente con Paracelso; para el médico suizo, muchos profesionales «sólo se preocupan de su propio espectáculo y propaganda, de ganar dinero y de disputar con aldeanos y gente profana, en vez de contender con verdaderos Filósofos, en provecho de su ciencia común» ${ }^{52}$.

\section{LA TERAPÉUTICA DE DIEGO DE SANTIAGO.}

A pesar de que en el Arte separatoria se aprecian direcciones intelectuales que suponen una gran separación con la ciencia tradicional, todavía se observan muchos rasgos que hacen que la obra del extremeño sea valorada, a mi juicio, como punto de partida, aunque no el único, de una nueva orientación científica que, como es bien sabido, en España no tuvo continuadores.

Gran parte de los conocimientos fisiológicos, patológicos y terapéuticos de la época en la que vivió Diego de Santiago, estaban impregnados de galenismo, aunque, como ya hemos referido anteriormente, se observaba una apertura a otros saberes. La indicación terapéutica galénica, basada en preceptos de origen hipocrático, tenía tres ejes fundamentales: el médico debe cooperar al esfuerzo sanador de la physis; hay que tratar las enfermedades con sus contrarios, contraria contrariis, y los remedios arrastran consigo, por semejanza, los elementos causantes de la dolencia, similia similibus ${ }^{53}$.

El sistema médico-filosófico de Galeno considera la enfermedad como un desorden de la naturaleza del paciente; por eso hace referencia a una «fuerza medicatriz de la naturaleza» que tiende a curar las pequeñas enfermedades y, sólo cuando la naturaleza no puede vencerla, se hace necesaria la ayuda médica. El origen de la terapéutica del extremeño se ajusta, en gran medida, a esta concepción del médico de Pérgamo: «nuestra naturaleza es la más perfecta de todas, y que no descubre la ofensa luego en recibiéndola: que primero asiste y resiste, y trabaja de contradezirle y digerir las tales cosas que le ofenden y disponerlas en otras sustancias» ${ }^{54}$.

La terapéutica galénica se basaba en: a)la naturaleza de la enfermedad: carácter de la misma, tipo, violencia, etc.; b)la naturaleza del órgano donde se asienta, ya que los hay secos, húmedos, fríos y calientes en diferentes grados; c)la constitución biológica del enfermo y d)los agentes externos nocivos, principalmente el aire ambiental y los sueños.

\footnotetext{
51 SANTIAGO, D. (1598b), p. 38.

52 PARACELSO (1992).«Libro de las paradojas», Libro III. «Acerca de las enfermedades producidas por el tártaro», p. 252.

53 Para más detalles sobre la terapéutica galénica puede consultarse el capítulo del mismo título de GARCÍA BALLESTER, L. (1972), Galeno. Guadarrama, Madrid.

54 SANTIAGO, D. (1598a), p. 75.
} 
El hígado, órgano fundamental de la anatomía y fisiología galénicas, merece una atención especial del extremeño. En el capítulo noveno de su Arte separatoria, «De las causas que ofenden al hígado», leemos una gran cantidad de conceptos del médico de Pérgamo mezclados con otros más modernos de claro origen paracelsista. El hígado, víscera fundamental del galenismo, lo es también del sistema médico de Paracelso: «las enfermedades del hígado siguen siendo las más importantes por ser el hígado un miembro de gran nobleza que sirve, ayuda e influye en casi todos los demás» ${ }^{55}$. En la misma línea, el extremeño dice que si hay una buena digestión en los estómagos y una buena expulsiva, el hígado no se inflamará; en caso contrario, si la expulsiva no es buena, se retendrán los excrementos que al corromperse provocarán muchas enfermedades: «dolores de cabeza, ardores de espaldas, y de hígado y de bazo y de vientre y de otras muchas partes». Y es porque con la expulsiva «se expelen las partes excrementicias», por lo que las purgas se utilizarán para «suplir las faltas de expulsiva».

Si al hígado (caliente y seco) se le pegan unos humores crudos y viscosos (fríos y húmedos), que se encuentran en las partes terrestres, se cerrarán los poros y vías, lo que provocará que se reconcentre el calor en él. Por ello, el problema puede solucionarse utilizando sustancias «muy rarificadas» que penetren en las vías y las abran, es decir, que «rarifiquen lo grueso que las cerró». El hígado, caliente y seco, es ofendido por la frialdad y la humedad: «porque yo he visto muchas personas que tenían grandes ynflamaciones de hígado, y aver usado mucho tiempo de remedios fríos y húmedos, y corpulentos, y no aver sentido ningún beneficio, sino antes notable daño» y si se destempla el hígado «en lugar de hazer y engendrar sangre, les engendrava agua». En este sentido De Santiago se aleja de los conceptos del médico de Einsideln, para el que las condiciones de las enfermedades pueden ser calientes o frías, pero no a la vez húmedas o secas y para el que «cuando un cuerpo se abrasa, es señal que algo, pero sólo una cosa, lo invade. Ese algo es el que lo dirige hacia el calor, el frío, la sequedad o la humedad, y que el médico debe investigar» ${ }^{56}$.

Los conceptos terapéuticos por los cuales las enfermedades han de ser tratadas por sus contrarios, contraria contrariis, aparecen en el texto del extremeño; así, por ejemplo, cuando explica las causas de las tercianas y cuartanas: si se engendra un humor crudo y viscoso, que es frío y húmedo, que se pega al estómago, bazo e hígado, y el calor natural consume la humedad y lo convierte en frío y seco, se necesitará una medicina que caliente y humedezca ${ }^{57}$

Diego de Santiago explica cómo ha obtenido los «espíritus del vino» y, posteriormente, nos dice que en los mismos ha echado «las cosas que me parecía conve-

55 PARACELSO (1992). «Libro de las paradojas», Libro III. «Acerca de las enfermedades producidas por el tártaro», p. 275.

56 PARACELSO (1992). «Libro de las paradojas», Libro I. «Causas y orígenes de las tres primeras sustancias». Renacimiento, C.S.I.C. Sevilla, p. 164-165.

57 SANTIAGO, D. (1598a), pp. 75-76. 
nir» a las enfermedades: perlesía, asma, gomas, cirros, opilaciones de bazo, estrangurrias, arenas de riñones, dolores de conyunturas, etc.; después, da cuenta de que ha utilizado esa medicina como bebida, en fomentaciones y «en casos de heridas y contusiones, usando de primera yntención» y todo lo ha hecho según lo que requería la enfermedad: «a los secos humedeciéndoles, y a los húmedos desecándoles y a los fríos calentándoles y a los calientes refrescándoles» ${ }^{58}$. Además, nuestros humores están protegidos, mediante túnicas, de la acción negativa de los contrarios y si éstas faltan, se produce la corrupción de aquéllos ${ }^{59}$.

Al hablar de una medicina que cura la lepra, los lamparones y toda especie de «humores viscosos», aplica el principio por el cual los remedios arrastran consigo, por semejanza, los elementos causantes de la dolencia: la medicina de calidad terrestre concuerda con las enfermedades terrestres y «por la dicha concordanza nos libra dellas» ${ }^{60}$.

En el capítulo 59 del Arte separatoria nos habla de una medicina para las cámaras y pujos, hecha con vino tinto, vinagre, romero, arrayán e incienso blanco. No podía faltar un medicamento para esta necesidad ya que una de las principales preocupaciones del hombre de la época, en relación con la salud, era defecar, esto es, «hacer cámara». Y es que de acuerdo con la medicina tradicional, al «corromperse» los excrementos no expulsados se producen vapores capaces de alterar la salud. Por todo ello, no es raro encontrar en las casas del siglo XVI laxantes y drásticos ${ }^{61}$.

De la misma manera que Paracelso entendía el mundo como una gran farmacia y decía: que «en el mismo lugar de la tierra donde existe un veneno mortal, existe también un contraveneno» ${ }^{62}$, Diego de Santiago afirma que las soluciones de las enfermedades se encuentran en la naturaleza «y de todo ello se dé gracias al Señor, pues lo crió para nuestro remedio» ${ }^{63}$.

\section{LOS REMEDIOS DE DIEGO DE SANTIAGO.}

Las especies vegetales con interés terapéutico que aparecen en el Arte separatoria son, ordenadas alfabéticamente, las siguientes: abrojo, achicoria, ajenjo, almáciga (es el árbol de la almáciga, o por otro nombre lentisco), altamisa, anís, arrayán, azafrán,

\footnotetext{
58 SANTIAGO, D. (1598a), pp. 26-28.

59 SANTIAGO, D. (1598a), p. 63.

60 SANTIAGO, D. (1598a), p. 86.

61 Sobre este asunto puede consultarse: RoJo VEGA, A. (1997). «Objetos medicinales y botiquín casero en el Siglo de Oro». Medicina e Historia, n1 68, pp. I-XVI.

62 PARACELSO (1992). «Libro de las paradojas», Libro I. «Causas y orígenes de las tres primeras sustancias», p. 195.

63 SANTiago, D. (1598a), p. 30.
} 
berro, borraja, calabaza, canela, caña de azúcar (cita el azúcar piedra), cañafístola, cardo ajonjero, cardo corredor, cardo santo, cebolla, cicuta, clavel, clavo, dormidera, eléboro negro, encina, escorzonera, esparraguera, granada, haba, hinojo, hipericón, incienso, limón, lentisco, llantén, macia, madroño, malva, manzanilla, melón, mirra, mostaza, naranjo amargo (cita el azahar), nuez moscada, olivo (nombra el aceite común) ororuz, opio, peonia redonda, perejil, pericón, pino, rábano, roble, romero, rosa castellana, sabina, salvia, sauco, tarache, trébol, trementina, trigo, valeriana, varrilla y vid.

La terapéutica vegetal utilizada por Diego de Santiago se ajusta, en líneas generales, a la que se observa en los médicos humanistas del siglo XVI español.

Diego de Santiago nos refiere de una manera muy concisa, y a modo de colofón a su Arte separatoria, los efectos concretos de los extractos de algunos de estos vegetales; así, cuenta el poder diurético del perejil y de la esparraguera, que «abre las vías de la orina», los efectos del romero, que «conforta el cerebro», las propiedades digestivas del ajenjo amargo, que «conforta el estómago» y otros más ${ }^{64}$; efectos sobradamente conocidos, que se pueden encontrar, por ejemplo, en los comentarios de Andrés Laguna a la clásica obra de Dioscórides: Pedacio Dioscorides Anazarbeo, acerca de la materia medicinal, y de los venenos mortíferos. (1566).

Diego de Santiago nos informa de la sabina y de la cañafístola, especie esta última que podría ser la oriental (Cassia fistula), la occidental (C. grandis) u otra del mismo género: «las cáscaras de la Cañafístola y de la Sabina provocan el menstruo de las mugeres» ${ }^{65}$. Este efecto no aparece en los textos de contemporáneos como Luis de Toro ${ }^{66}$ o Nicolás Monardes ${ }^{67}$ que, entre otras cosas, destacan los efectos purgativos de la planta. En cuanto a la sabina (Juniperus sabina), el médico segoviano Andrés Laguna le atribuye la misma propiedad que el extremeño: «es yerva muy conocida de las mugeres, porque ordinariamente beven su cozimiento, para provocar la purgation represada ${ }^{68}$.

Sin poder precisar si Santiago se refiere a especies del género Lagenaria, de origen europeo, o a la especie americana Cucurbita pepo, nos habla de la utilidad de las semillas de calabaza, junto con otras plantas, para las calenturas; lo que se ajusta a la

\footnotetext{
64 SANTIAGO, D. (1598b), p.67.

65 SANTIAGO, D. (1598b), pp. 67-68

66 TORO, L. (1941). De la fiebre epidémica y nueva, en latín punticular, vulgarmente tabardillo y pintas. Su naturaleza, conocimiento y medicación. Biblioteca clásica de la Medicina española XIII. Real Academia de Medicina. Madrid, p. 236.

67 MONARDES, N. (1574). Primera y segunda y tercera partes de la Historia medicinal de las cosas que se traen de nuestras Indias occidentales que sirven en medicina ... Edición facsímil de Padilla Libros. Sevilla, 1988, pp. 25-26.

68 Laguna, A. (1566). Pedazio Dioscorides anazarbeo, acerca de la materia medicinal, y de los venenos mortiferos, ... (I). Mathias Gast. Salamanca. Edición facsímil de MRA. Andreu, 1994, p. 63.
} 
lógica de la medicina galénica en cuanto a que eran consideradas «semillas frías» (junto con las de cohombrillo, sandía y melón).

Una especie que aparece numerosas veces en la farmacopea de la época es la hierba escorzonera (Scorzonera hispanica). Nuestro alquimista la nombra en varias ocasiones, ya sola para curar humores melancólicos ${ }^{69}$, ya con otros vegetales para sanar, por ejemplo, las fiebres tercianas y cuartanas ${ }^{70}$. Hay que recordar que de las excelencias de la raíz de escorzonera había hablado Monardes, que contaba su utilización, sacando «el agua por alambique o alquitara», como golosina, para los desmayos, fiebres, opilaciones de hígado y bazo, ausencia de menstruo, etc. ${ }^{71}$; por supuesto que en la extensa relación de propiedades de la planta, también servía contra las «tristezas de corazón y melancolías». Sobre la otra propiedad que refiere de Santiago se puede decir que el médico placentino Luis de Toro habla de ella como de una raíz «muy conveniente para la fiebre pulicar» ${ }^{72}$.

Para curar la gota coral, también llamada alferecía, el extremeño utiliza escorzonera, peonía redonda, flor de romero y de borraja, con lo que se ajusta en gran medida a la farmacopea tradicional. Así, el romero es para Laguna muy útil contra las enfermedades frías de cabeza ${ }^{73}$, como era considerada la alferecía.

Por otra parte, y desde tiempos muy antiguos, se utilizaban diversas partes de la peonía (Paeonia officinalis, L.) contra la epilepsia. Andrés Laguna destaca lo admirable de la simiente y de la raíz, bebida o colgada del cuello, para curar esta enfermedad, sobre todo en los niños ${ }^{74}$; esto aparece también en el Methodo y orden de curar las enfermedades de los niños (1600), del médico aragonés Jerónimo Soriano: «Colgáranle al cuello cuentas de simiente de peonía o de raíces della, cogidas en luna menguante» ${ }^{75}$.

Diego de Santiago también recurre al mundo animal en su recetario, algo frecuente en la farmacopea de la época: culebras contra la lepra, lamparones y humores viscosos; elementos de origen animal y vegetal mezclados: agua de malvas, de habas, aźafrán, agua de leche de cabras y culebras vivas contra la lepra seca; o cebollas blancas, levadura, aceite de manzanilla, manteca de cerdo y yema de huevo que, como ungüento contra los incordios, se aplicará en hojas de llantén ${ }^{76}$.

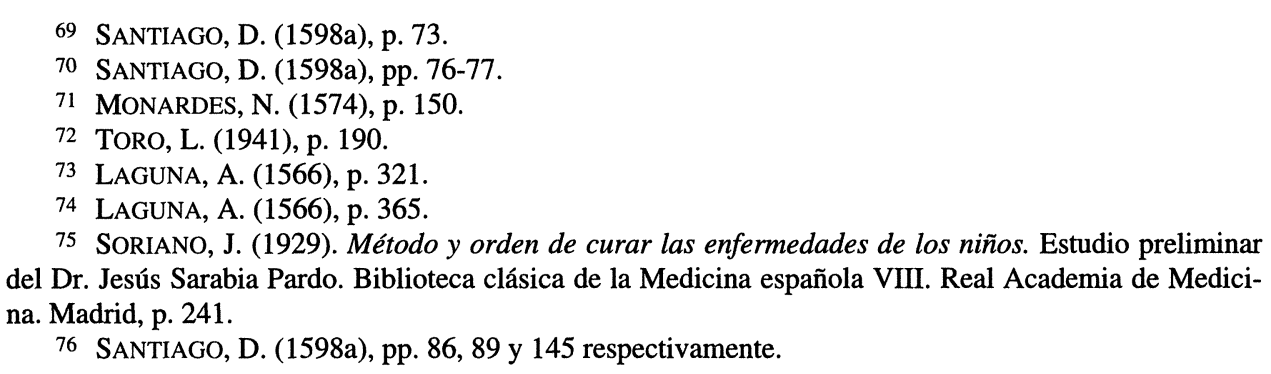


Andrés Laguna nos dice que del azogue calcinado con agua fuerte se hace el «polvo de Ioannes de Vigo», que bebido con vino es excelente para el mal francés ${ }^{77}$. De Santiago aplica su arte separatoria a lo que ya se sabía en la medicina humanística: si se calcina y limpia de manera que con este proceso se elimine la sulfuridad y la humedad excrementicia (conceptos de los que hablaremos después) el azogue, venenoso, se transformará en medicina; en caso contrario, continuará siendo veneno ${ }^{78}$.

\section{LA PERSONALIDAD MÉDICO-ALQUÍMICA DE DIEGO DE SANTIAGO.}

El extremeño no es reacio a utilizar términos científicos creados por él. Sugiere la modificación del término quintas esencias por el de quintas calcinaciones, ya que no por mucho destilar es posible separar «las partes sutiles de las gruesas, ni las leves de las graves, sino se procede primero en las tales cosas con las digestiones y grados de calor ${ }^{79}$. Es decir, antes de cualquier destilación, y para Santiago esto es lo fundamental, es necesario macerar, «digerir», los productos naturales y posteriormente aplicar los diferentes grados de calor, o lo que es igual, el calor aportado por el baño de agua, baño de arena, retortas, fuego directo, etc.

Quizás el aspecto más llamativo de toda la obra del extremeño es el que se refiere a la existencia del «sulfre conservador», que preserva nuestros humores de la corrupción, y del «sulfre corrompedor», que altera los humores ${ }^{80}$. Por esto, el conocimiento de la sulfuridad es fundamental, ya que la medicina ideal, que curará cualquier enfermedad, será la concordante con el «sulfre nature o sulfre conservador» ${ }^{81}$; en consecuencia, las medicinas deben quedar libres del «sulfre corrompedor» ${ }^{82}$.

Para nuestro autor, los «salsos» y los «grasos» son «las sustancias más principales que en la naturaleza hay», porque son componentes de todos los cuerpos y nos preservạn de la corrupción. Se distribuyen de la siguiente manera: «en lo caliente y húmedo hay mucho graso y poco salso y en lo caliente y seco mucho salso y poco graso, y en lo frío y húmedo, ningún salso, y poco graso, y en lo frío y seco poco salso y ningún graso» ${ }^{83}$. Además, «todos los salsos y grasos tienen su sulfre natura» ${ }^{84}$. De la utilidad de estas sustancias da cuenta el capítulo 11 del primer libro del Arte; se fun-

77 LAGUNA, A. (1566), pp. 542 y 592.

78 SANTIAGO, D. (1598b), p. 11.

79 SANTIAGO, D. (1598), p. 21.

80 Para más detalles sobre los sulfres, salsos, grasos y otros aspectos de la alquimia de Diego de Santiago puede consultarse, TEIXIDÓ GÓMEZ, F. y FERRERA ESCUDERO, S. (1998), Op. cit. pp. 31-47.

81 SANTIAGO, D. (1598b), pp. 15-19.

82 SANTIAGO, D. (1598b), p. 69.

83 SANTIAGO, D. (1598a), pp. 44-45.

84 SANTIAGO, D. (1598a), p. 79. 
damenta en el hecho de que la materia muerta no se corrompe con la sal: «lo salso preserva de la corrupción»; por otro lado, el graso «nos sustenta».

He comentado anteriormente el cariz alquímico de los procesos fisiológicos, pero es en el capítulo 36, dedicado a explicar las virtudes del salso y del graso, cuando deja bastante claro que hay que separar la parte terrestre de todas las sustancias que se utilicen con fines terapéuticos. Para explicarlo aduce dos importantes razones fisiológicas: la imposibilidad que tiene la naturaleza para digerir o transmutar las partes terrestres en otras sustancias. Utiliza un ejemplo que aclara el asunto: si una hierba purgativa se destila y se utiliza el agua resultante como purgante, carece de esta propiedad; por tanto, la sustancia purgante está en el residuo seco, lo que se puede comprobar disolviendo éste en agua y utilizándolo con fines purgativos. Ahora bien, si se separa el salso y graso del resto, se verá que el primero purga y el residuo terrestre no.

De Santiago utiliza aspectos paracelsistas, como los relativos a los sabores, a la hora de explicar el «clásico» examen de la orina, propio de la medicina de la época. La orina de un sano y de un enfermo se diferencian en el color: la del primero tiene color áureo, la del segundo tiene alterado este color; la sal de la orina del sano es blanca y de buen gusto, la del enfermo tiene poca sal ${ }^{85}$. Aunque se pronuncia claramente a favor de las tria prima paracelsistas: azufre, mercurio y sal, que junto con la tierra forma parte de cualquier sustancia, en el análisis de las orinas se aprecia un acercamiento mayor a la fisiología del médico suizo que considera que la vejiga de la orina rechaza la sal ${ }^{86}$.

También es posible utilizar el análisis de la orina destilándola y comprobando «el color de la humosidad que se levantare, y si fuere roja es movida la sangre, y si fuere la humosidad parda es movida la melancolía...» etc. De la ceniza de la destilación hay que separar el salso y graso y comprobar su sabor: «si fuere dulce es alterada la sangre, y si fuere amarga es la cólera...», etc. ${ }^{87}$.

El sistema del médico de Pérgamo utilizaba además el estudio de las dynámeis o las cuatro fuerzas en las que se expresa la naturaleza animal: atractiva, retentiva, alterativa y expulsiva. Pues bien, aplicando el principio galénico por el que en la expulsiva se encuentra la acción sanadora, Diego de Santiago se refiere a ciertas medicinas «nobles» que lo son porque actuan «fortificando nuestro celebro y el calor natural, con el qual se esfuerza la expulsiva con que se espelen los excrementos que nuestro calor no digiere» ${ }^{88}$.

De Santiago, con una clara orientación paracelsista, apela a las «influencias celestes» como responsables de las transmutaciones de los elementos; la causa de la

85 SAntiago, D. (1598a), pp. 44-45.

86 PARACELSO (1992). «Libro de las entidades», Segundo «Libro pagano acerca de las entidades morbosas. Tratado de la entidad del veneno». p. 83.

87 SANTIAGO, D. (1598a), p. 14.

88 SANTIAGO, D. (1598a), p. 74. 
transmutación de los humores es «nuestro cielo corporal, que es el celebro, del cual bajan aquellos espíritus los cuales mueven, y vivifican, y dan ser a todas las cosas». Además, muchos de los materiales que se utilizan en la medicina manifiestan unas calidades que son «espirituosas», «celestes» e «invisibles» a nuestros ojos ${ }^{89}$. Paracelso estaba en contra de los médicos que no tomaban el cielo en consideración y todo lo atribuían al «microcosmos»; para el médico suizo el calor del hombre procede de la unión de cosas celestes, terrestres, acuáticas y aéreas ${ }^{90}$.

Según el galenismo, los medicamentos, de acuerdo con su composición, se clasifican en «simples», no mezclados, y «compuestos», elaborados con diferentes simples. Sin embargo, para Santiago no existen los simples: «como es verdad que no hay cosa simple, nómbrolos yo compuestos» ${ }^{91}$. Esta opinión es recalcada al final del primer libro del $A r t e^{92}$ en el que llega a decir que ni siquiera los elementos son simples: «en el agua se halla tierra, y salso y graso...Y en la tierra se halla salso, y graso, y «Aire, y Agua»; y cuando dice: «Porque hoy se usa llamar simple a una hierba o palo o droga, o medio mineral, y a todas las demás cosas llaman simples: y ninguna cosa hay simple, por mínima que sea. Porque todas son compuestas» y precisamente la función del «arte» es la de extraer los simples de distintas sustancias compuestas, haciendo uso de las «digestiones» y de los «grados de calor». Aunque en una página precedente había dicho que «si hay algún elemento simple es el fuego», ahora los nombra: los «leves» $\mathrm{y}$ «graves», lo «sutil» y lo «grueso», la «sequedad», el «calor» $\mathrm{y}$ la «frialdad».

89 SANTIAGO, D. (1598b), pp. 56-58.

90 PARACELSO (1992). «Libro de las paradojas», Libro II. «Causas y orígenes de las enfermedades que provienen de las tres primeras sustancias», p. 202.

91 SANTIAGO, D. (1598a), p. 53.

92 Santiago, D. (1598a), pp. 133-136. 